\title{
A Concise Route to Dihydrobenzo[b]furans: Formal Total Synthesis Of (+)- Lithospermic Acid
}

\author{
${\text { Joshua Fischer, }{ }^{\dagger} \text { G. Paul Savage }}^{\ddagger}$ and Mark J. Coster, ${ }^{*}$ \\ Eskitis Institute For Cell And Molecular Therapies, Griffith University, Nathan 4111 \\ Queensland, Australia and CSIRO Materials Science and Engineering, Private Bag 10, \\ Clayton 3169 Victoria, Australia.
}

m.coster@griffith.edu.au

Received Date (will be automatically inserted after manuscript is accepted)

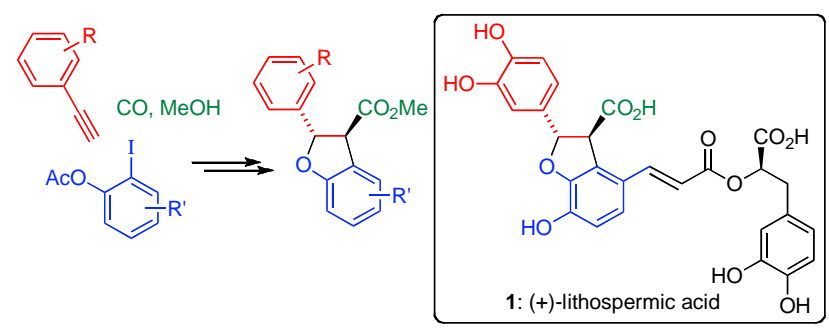

A sequence of Sonogashira coupling, $\mathrm{Pd}(\mathrm{II})$-catalyzed carbonylative annulation and benzofuran reduction (Mg, $\mathrm{MeOH}, \mathrm{NH}_{4} \mathrm{Cl}$ ) provides a convergent and modular synthetic route to trans-2-aryl-2,3-dihydrobenzo[b]furan-3carboxylates, which are a common structural feature of a number of biologically active natural products. This versatile strategy has been applied to the formal total synthesis of the anti-HIV natural product (+)-lithospermic acid.

2-Aryl-2,3-dihydrobenzo[b]furans are a common structural feature of numerous natural products (e.g. 1-2, Figure 1) exhibiting wide-ranging bioactivities, including antimitotic ${ }^{1}$, antiangiogenic ${ }^{2}$ antioxidant, ${ }^{3}$ antimicrobial, ${ }^{4}$ and neuritogenic ${ }^{5}$ activities. The majority of natural products isolated with this skeleton are 2,3-trans

\footnotetext{
${ }^{\dagger}$ Eskitis Institute for Cell and Molecular Therapies, Griffith University. ${ }^{\ddagger}$ CSIRO Materials Science and Engineering.

${ }^{1}$ Pieters, L.; Van Dyck, S.; Gao, M.; Bai, R.; Hamel, E.; Vlietinck, A.; Lemière, G. J. Med. Chem. 1999, 42, 5475-81.

2 Apers, S.; Vlietinck, A; Pieters, L Phytochem. Rev. 2003, 2, 201-217.

${ }^{3}$ Kikuzaki, H.; Kayano, S.; Fukutsuka, N.; Aoki, A.; Kasamatsu, K.; Yamasaki, Y.; Mitani T.; Nakatani, N. J. Agric. Food Chem. 2004, 52, 344-349.

${ }^{4}$ Pauletti, P.M; Araújo, A.R.; Young, M.C.M.; Giesbrecht, A.M.; Bolzani, V.S. Phytochemistry 2000, 55, 597-601.

${ }^{5}$ Shin, J.S.; Kim, Y.M.; Hong, S.S.; Kang, H.S.; Yang, Y.J.; Lee, D.K.; Hwang, B.Y.; Ro, J.S.; Lee, M.K. Arch. Pharm. Res. 2005, 28, 13371340 .
}

configured, ${ }^{6}$ with many that were initially assigned as cisconfigured having their relative stereochemistry revised. ${ }^{7}$

Figure 1. Representative dihydrobenzo[b]furan natural products
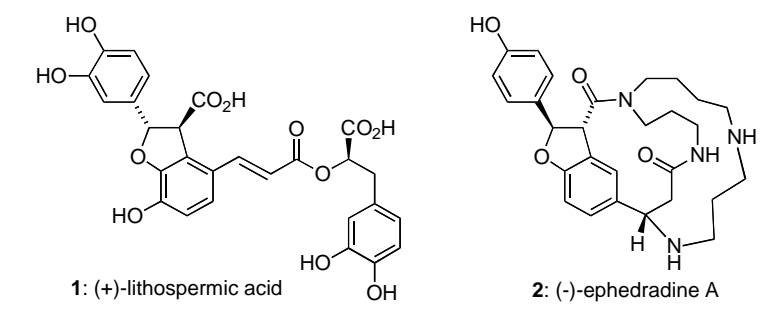

\footnotetext{
${ }^{6}$ Sefkow, M. Synthesis 2003, 2595-2625.

Li, S.; Iliefski, T.; Lundquist, K; A.F.A. Wallis. Phytochemistry, 1997, 46, 929-934.
} 
Considerable effort has been devoted to the synthesis of 2aryl-2,3-dihydrobenzo[b]furans. Strategies employed for the diastereoselective synthesis of these systems ${ }^{8}$ include the biomimetic oxidation of phenylpropenes, the Schmidt rearrangement, the rearrangement of chalcone epoxides and acid catalysed [3+2] cycloadditions of phenylpropenes with quinones. ${ }^{6}$ Enantioselective syntheses have also been achieved via $\mathrm{Rh}(\mathrm{II})$-catalyzed intramolecular $\mathrm{C}-\mathrm{H}$ insertions, ${ }^{9,10}$ with this approach affording a predominance of the cis-2,3-dihydrobenzo[b]furan.

The closely related 2,3-disubstituted benzo[ $b]$ furans have attracted extensive synthetic interest and also exhibit a broad range of biological activities. ${ }^{11}$ Among available strategies for the synthesis of benzo[b]furans, palladiumcatalyzed cyclizations are particularly attractive, allowing for the simultaneous installation of a carbonyl substituent at $\mathrm{C} 3$, to give the 2,3-disubstituted systems. ${ }^{12}$ Our synthetic approach would provide access to both 2-arylbenzo[b]furan and 2-aryl-2,3-dihydrobenzo[b]furan-containing natural products and analogues. Key to the success of the approach was developing a method to reduce the benzo[b]furan system to the corresponding trans-2,3dihydrobenzo[b]furan. The retrosynthetic strategy depicted in Scheme 1 highlights the concise and highly modular approach we proposed to access this class of compounds.

Scheme 1. Retrosynthetic Analysis of 2-aryl-2,3dihydobenzo[b]furans-3-carboxylates (3)

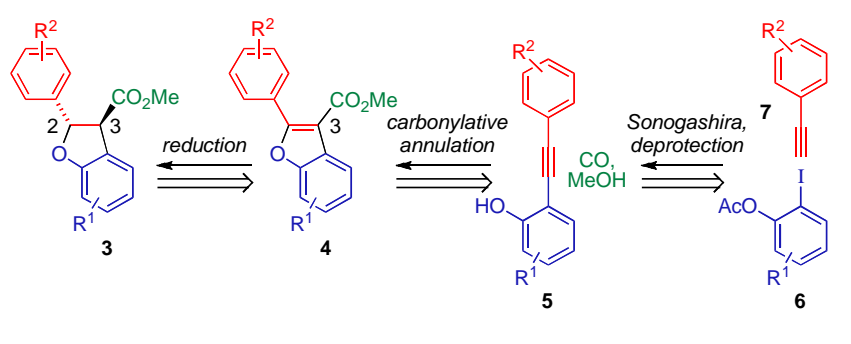

We envisaged that dihydrobenzofuran 3 would be formed by stereoselective reduction of benzofuran 4, which would be derived from ortho-hydroxydiarylalkyne 5, using a carbonylative annulation reaction. ortho-

\footnotetext{
${ }^{8}$ Graening, T.; Thrun, F. Comprehensive Hetereocyclic Chemistry III; Katritzky, A.R.; Taylor, R.J.K.; Ramsden, C.A.; Scriven, E.F.V. Eds. Elsevier, 2008; Vol. 3, 553-561 and references cited therein.

${ }^{9}$ García-Muñoz, S.; Álvarez-Corral, M.; Jiménez-González, L.; LópezSánchez, C.; Rosales, A.; Muñoz-Dorado, M.; Rodríguez-García, I. Tetrahedron, 2006, 62, 12182-90.

${ }^{10}$ Natori, Y.; Tsutsui, H.; Sato, N.; Nakamura, S.; Nambu, H.; Shiro, M.; Hashimoto, S. J. Org. Chem. 2009, 74, 4418-4421.

11 For recent synthetic strategies see: (a) Kao, C-L.; Chern, J-W. J. Org. Chem. 2002, 67, 6772-6787. (b) Cho, C-H.; Neuenswander B.; Lushington, G.H.; Larock, R.C. J. Comb. Chem. 2008, 10, 941-47. (c) Duan, S-F.; Shen, G.; Zhang, Z-B.; Synthesis, 2010, 15, 2547-52 (d) Bang,, H.B.; Han, S.Y. Choi, D.H.; Yang, D.M.; Hwang, J.W. Lee, H.S.; Jun, J-G. Synth. Commun. 2009, 39, 506-515. (e) Scammells, P.J.; Baker, S.P.; Beauglehole, A.R. Bioorg. Med. Chem. 1998, 6, 1517-1524.

${ }^{12}$ For examples, see: (a) Kondo, Y.; Sakamoto, T.; Yamanaka, H. Heterocycles 1989, 29, 1013-1016. (b) Lutjens, H.; Scammells, P. J. Tetrahedron Lett. 1998, 39, 6581-6584. (c) Nan, Y.; Miao, H.; Yang, Z. Org. Lett. 2000, 2, 297-299.
}

Hydroxydiarylalkyne 5 would be derived from the Sonogashira coupling of protected aryl iodide $\mathbf{6}$ and arylalkyne 7. Initial investigations focused on the development of this route, using aryl iodides $(\mathbf{8}, \mathbf{9})$ and a range of terminal alkynes (10-16). Subsequently, the utility of this method was demonstrated through the formal total synthesis of the anti-HIV natural product (+)-lithospermic acid (1).

The required diarylalkyne substrates were synthesised by Sonogashira coupling of aryl iodide $\mathbf{8}^{13}$ with arylalkynes $\mathbf{1 0 - 1 4},{ }^{14}$ and aryl iodide $\mathbf{9}^{15}$ with arylalkynes $\mathbf{1 4 - 1 6}$ (Table 1). Traditional coupling conditions were well-suited for generating diarylalkynes 17a-e (Method A), however yields of $\mathbf{1 8 b}$ and $\mathbf{1 8 c}$ were improved by using the conditions of Andrus et al. ${ }^{16}$ (Method B). De-acetylation of 17a-e was hampered by a competing side-reaction that produced unwanted protio-cyclized benzofurans, which lacked the carbomethoxy functionality at the 3-position. Through the use of $\mathrm{Cs}_{2} \mathrm{CO}_{3}$ in $\mathrm{MeOH}-\mathrm{THF}$ at $0{ }^{\circ} \mathrm{C}$, orthohydroxydiarylalkynes 19a-e were afforded in good yield with no appreciable protio-cyclization.

Table 1. Synthesis of ortho-hydroxydiarylalkynes

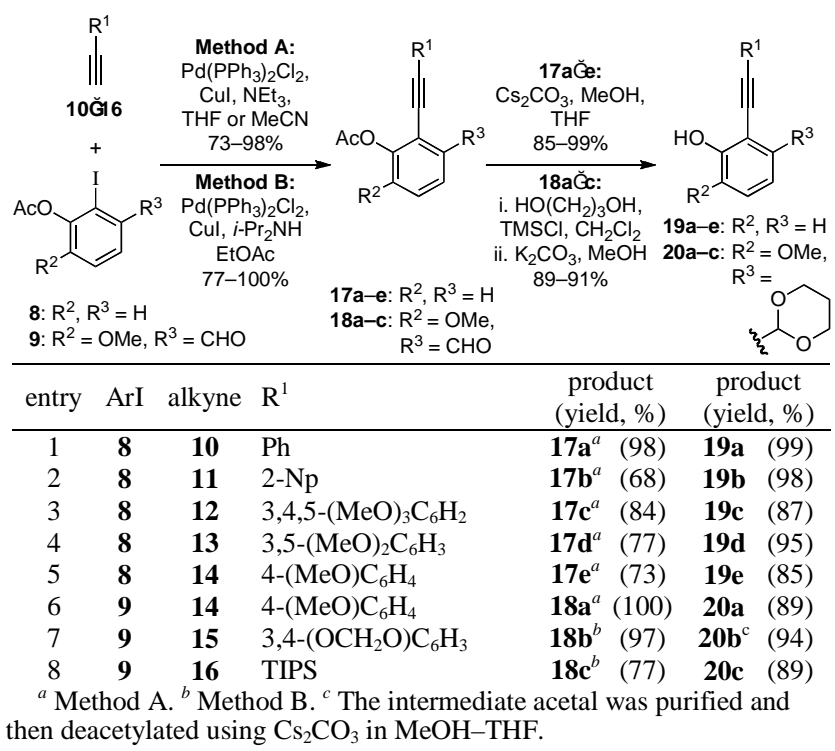

At this stage it was necessary, in the case of benzaldehydes 18a-c (Table 1), to protect the aldehyde

\footnotetext{
${ }^{13}$ Miao, H.; Yang, Z; Org. Lett. 2000, 2, 1765-68.

14 Alkynes 10, 13 and $\mathbf{1 6}$ were commercially available. All other alkynes were prepared from the corresponding aldehyde by the CoreyFuchs alkynylation procedure: Corey, E. J.; Fuchs, P. L. Tetrahedron Lett. 1972, 36, 3769-3772.

15 See supporting information for the acetate protection of 2iodoisovanillin, which was prepared according to Markovich, K. M.; Tantishaiyakul, V.; Hamada, A.; Miller, D. D.; Romstedt, K. J.; Shams, G.; Shin, Y.; Fraundorfer, P. F.; Doyle, K.; Feller, D. R. J. Med. Chem. 1992, 35, 466-479.

${ }^{16}$ Andrus, M. B.; Lepore, S. D.; Turner, T. M. J. Am. Chem. Soc. 1997, 119, 12159-12169.
} 
Table 2. Carbonylative Annulation and Mg-mediated benzofuran reduction

\begin{tabular}{|c|c|c|c|c|c|c|c|c|c|}
\hline \multirow{3}{*}{$\begin{array}{c}\text { entry } \\
1\end{array}$} & \multirow{3}{*}{$\begin{array}{c}\text { substrate } \\
\mathbf{1 9 a}\end{array}$} & \multirow{2}{*}{$\begin{array}{l}\begin{array}{c}19 a-e \\
20 a-c\end{array} \\
\mathrm{R}^{1}\end{array}$} & 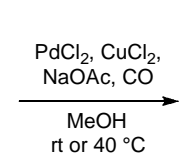 & 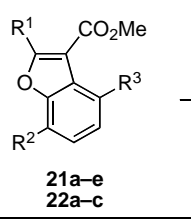 & $\begin{array}{c}\underset{\mathrm{Mg}, \mathrm{MeOH},}{\mathrm{NH}_{4} \mathrm{Cl}} \\
-15^{\circ} \mathrm{C} \text { to rt }\end{array}$ & \multicolumn{2}{|c|}{ 24a-ber } & & \multirow[b]{2}{*}{ trans:cis $^{b}$} \\
\hline & & & $\mathrm{R}^{2}$ & $\mathrm{R}^{3}$ & & & $\begin{array}{r}\text { pro } \\
\text { (yiel }\end{array}$ & $\begin{array}{l}\text { luct } \\
\left.\text {, }^{a}\right)^{a}\end{array}$ & \\
\hline & & $\mathrm{Ph}$ & $\mathrm{H}$ & $\mathrm{H}$ & $21 \mathrm{a}$ & $(69)$ & $23 a$ & $(84)^{c}$ & $94: 6$ \\
\hline 2 & $19 b$ & 2-Np & $\mathrm{H}$ & $\mathrm{H}$ & $21 b$ & (86) & $23 \mathbf{b}$ & $(36)^{d}$ & $85: 15$ \\
\hline 3 & $19 \mathrm{c}$ & $3,4,5-(\mathrm{MeO})_{3} \mathrm{C}_{6} \mathrm{H}_{2}$ & $\mathrm{H}$ & $\mathrm{H}$ & 21c & (80) & $23 c$ & (79) & $95: 5$ \\
\hline 4 & 19d & $3,5-(\mathrm{MeO})_{2} \mathrm{C}_{6} \mathrm{H}_{3}$ & $\mathrm{H}$ & $\mathrm{H}$ & 21d & (87) & 23d & $(66)^{e}$ & $91: 9$ \\
\hline 5 & $19 e$ & 4- $(\mathrm{MeO}) \mathrm{C}_{6} \mathrm{H}_{4}$ & $\mathrm{H}$ & $\mathrm{H}$ & $21 e$ & (77) & $23 \mathbf{e}$ & (85) & $95: 5$ \\
\hline 6 & $20 a$ & $4-(\mathrm{MeO}) \mathrm{C}_{6} \mathrm{H}_{4}$ & $\mathrm{MeO}$ & 1,3-dioxan-2-yl & $22 a$ & $(55)^{f}$ & $24 \mathbf{a}^{g}$ & (74) & $81: 19$ \\
\hline 7 & $20 b$ & $3,4-\left(\mathrm{OCH}_{2} \mathrm{O}\right) \mathrm{C}_{6} \mathrm{H}_{3}$ & $\mathrm{MeO}$ & 1,3-dioxan-2-yl & 22b & $(75)^{h}$ & $\mathbf{2 4 \mathbf { b } ^ { g }}$ & $(86)^{i}$ & $71: 29$ \\
\hline 8 & 20c & TIPS & $\mathrm{MeO}$ & 1,3-dioxan-2-yl & $22 c$ & $(0)^{\prime}$ & - & - & - \\
\hline
\end{tabular}

${ }^{a}$ Isolated yield of the trans-isomer. ${ }^{b}$ Determined by ${ }^{1} \mathrm{H}$ NMR of crude isolate. ${ }^{c}$ By-product isolated, $\mathrm{R}^{1}=$ cyclohex-2-enyl $(6 \%) .{ }^{d}$ By-products isolated, $\mathrm{R}^{1}=1$,2-dihydronaphthalen-2-yl (38\%); $\mathrm{R}^{1}=1,2,3,4$-tetrahydronaphthalen-2-yl (24\%). ${ }^{e}$ Reduction by-product isolated, $\mathrm{R}^{1}=3,5$-dimethoxycyclohexa-2,5dienyl (15\%). ${ }^{f}$ Accompanied by $8 \%$ of the trans-acetalised benzofuran product, analogous to 22a where $\mathrm{R}^{3}=\mathrm{CH}(\mathrm{OMe})_{2}{ }^{g}{ }^{g}$ Aqueous acid workup led to acetal hydrolysis, providing the benzaldehyde $\left(\mathrm{R}^{3}=\mathrm{CHO}\right)$ directly. ${ }^{h}$ Accompanied by $c a .10 \%$ of the dimethyl acetal, where $\mathrm{R}^{3}=\mathrm{CH}(\mathrm{OMe})_{2} .{ }^{i} \mathrm{Combined}$ yield of cis and trans. ${ }^{j}$ Trans-acetalised starting material isolated, analogous to $20 \mathrm{c}$ where $\mathrm{R}^{3}=\mathrm{CH}(\mathrm{OMe})_{2}$.

functionality in preparation for the carbonylative annulation and subsequent reduction step. Thus, benzaldehydes 18a-c were subjected to a one-pot procedure that included protection of the aldehyde as the corresponding cyclic acetal, followed by in situ methanolysis of the acetate, to reveal the orthohydroxydiarylalkynes 20a-c.

The carbonylative annulation conditions of Kondo ${ }^{12 a}$ and Scammells ${ }^{12 b}$ were found to be well-suited to our systems (Table 2). Applying these conditions to orthohydroxydiarylalkynes $19 a-\mathbf{a}$ and $20 \mathbf{a}-\mathbf{c}$, moderate to excellent benzofuran product yields were achieved for all but 20c (entry 8, Table 2). Reaction rates were enhanced by heating to $40{ }^{\circ} \mathrm{C}$, however, this had a detrimental effect on the yield of $22 \mathbf{a}-\mathbf{b}$, so these reactions were conducted at rt. Interestingly, methyl acetal by-products, resulting from trans-acetalization, were observed in the cases of 1,3dioxane substrates $20 a-\mathbf{c}^{17}$

Synthetic methods for reducing 2-arylbenzo[b]furan-3carboxylates to the corresponding 2-aryl-2,3dihydrobenzo[b]furan-3-carboxylate are scarce. Juhász et $a^{18 \mathrm{~b}}$ employed catalytic hydrogenation over $\mathrm{Pd} / \mathrm{C}$ in methanol to reduce methyl 2-phenylbenzo[b]furan-3carboxylate to the corresponding cis-2,3dihydrobenzo[b]furan in a low $11 \%$ yield. Whilst catalytic reduction of simpler benzofuran systems has provided cisdihyrobenzofurans, ${ }^{7}$ to the best of our knowlegdge, no methods for the reduction of 2,3-disubstituted

17 The methyl acetal counterparts could be separated by column chromatography, or carried on as a mixture with the 1,3-dioxane to the subsequent step.

${ }^{18}$ (a) Tamura, K.; Kato, Y.; Ishikawa, A.; Kato, Y.; Himori, M.; Yoshida, M.; Takashima, Y.; Suzuki, T.; Kawabe, Y.; Cynshi, O.; Kodama, T.; Niki, E.; Shimizu, M. J. Med. Chem. 2003, 46, 3083-3093. (b) Juhász, L.; Szilágyi, L.; Antus, S.; Visy, J.; Zsila, F.; Simonyi, M. Tetrahedron 2002, 58, 4261-4265. benzo[b]furans to the trans-dihydrobenzofuran have been reported. Common reduction conditions (e.g. $\mathrm{H}_{2} / \mathrm{Pd}-\mathrm{C}{ }^{18}$ chiral "CuH", ${ }^{19} \mathrm{TFA} / \mathrm{Et}_{3} \mathrm{SiH}^{20}$ ) applied to more complex benzofurans of type $\mathbf{2 1}$ and 22, showed that none of these conditions were suitable for our systems: either recovered starting material or complex mixtures of products were obtained. Our investigations concentrated on using magnesium in $\mathrm{MeOH}$ to effect this reduction. Chemoselective reduction of $\alpha, \beta$-unsaturated esters has been reported to proceed under these conditions even in systems in which the double bond is part of an aromatic system. ${ }^{21}$ Our substrates provided a considerable challenge, requiring chemoselective reduction of a tetrasubstituted double bond within an aromatic system. Early attempts at the $\mathrm{Mg}-\mathrm{MeOH}$ reduction proved low yielding and highly capricious, apparently due to low and variable activity of the magnesium and the low solubility of our substrates in $\mathrm{MeOH}$. The addition of THF as a co-solvent alleviated solubility issues, but also resulted in markedly less active magnesium. Attempts to activate the magnesium surface by stirring vigorously (both neat and in solution), by addition of $\mathrm{I}_{2}$ or 1,2-dibromoethane, or by prior treatment with dilute acid all proved inadequate or capricious. The introduction of $\mathrm{NH}_{4} \mathrm{Cl}$ to the reaction mixture as an agent

19 (a) Hughes, G.; Kimura, M.; Buchwald, S.L. J. Am. Chem. Soc 2003, 125, 11253-11258. (b) Appella, D.H.; Moritani, Y.; Shintani, R.; Ferreira, E.M.; Buchwald, S.L. J. Am. Chem. Soc. 1999, 121, 9473-9474.

(a) Rupprecht, K.M.; Boger, J.; Hoogsteen, K.; Nachbar, R.B.; Springer, J.P. J. Org. Chem. 1991, 56, 6180-6188. (b) Lanzilotti, A.E.; Littell, R.; Fanshawe, W.J.; McKenzie, T.C.; Lovell, F.M. J. Org. Chem. 1979, 44, 4809-4813.

(a) Boyle, E.A.; Mangan, F.R.; Markwell, R.E.; Smith, S.A.; Thomson, M.J.; Ward, R.W.; Wyman, P.A. J. Med. Chem. 1986, 29, 894898. (b) Youn, I.K.; Yon, G.H.; Pak, C.S. Tetrahedron Lett. 1986, 27, 2409-2410. (c) Lee, G.H.; Youn, I.K.; Choi, E.B.; Lee, H.K.; Yon, G.H.; Yang, H.C.; Pak, C.S. Curr. Org. Chem. 2004, 8, 1263-1287. 
for $\mathrm{Mg}$ activation , ${ }^{22}$ was crucial to obtaining reproducible results and, gratifyingly, enabled the use of THF as cosolvent without deleterious effects on reaction rate and yield. Pleasingly, these conditions proved amenable to all the benzofuran substrates (Table 2) in our investigation. The reduction reactions were observed to initially proceed with some degree of diastereoselectivity for the cisisomers, which then undergo magnesium methoxide promoted epimerisation to the more thermodynamically stable trans-isomers, 23a-e and $\mathbf{2 4 a}-\mathbf{b} .^{23}$ Partial reduction of the pendant $\mathrm{R}^{1}$ aryl group was observed to compete with the desired 2,3-reduction in some substrates (Table 2, entries 1-2, 4). However, these unwanted reductions could be minimised by lowering the reaction temperature from $\mathrm{rt}$ to $-15{ }^{\circ} \mathrm{C}$. To obtain optimal yields of the trans diastereomer the reaction mixture was decanted from excess $\mathrm{Mg}$ when reduction was complete, allowing the magnesium methoxide reaction mixture to warm to rt, whereupon epimerization to the predominantly transisomer resulted. The protected aldehyde in $\mathbf{2 2 a} \mathbf{a}-\mathbf{b}$, was unmasked by aqueous acid workup to afford the aldehyde products 24a-b directly.

Having demonstrated the carbonylative annulationreduction procedure to be a powerful, modular strategy for the synthesis of methyl 2-aryl-2,3-dihydrobenzo[b]furan-3carboxylates, we sought to further highlight the versatility of this approach through the synthesis of lithospermic acid (1). (+)-Lithospermic acid (1) was first isolated from Lithospermum ruderale in $1963^{24}$ and its structure elucidated in $1975 .^{25}(+)$-Lithospermic acid (1) has also been isolated from Salvia miltiorrhiza (Danshen), a popular herb in traditional Chinese medicine, ${ }^{26}$ and from many other sources. ${ }^{27}$ It was not until 2002 that it was found to be a potent HIV integrase inhibitor. ${ }^{28}$ Importantly, 1 was devoid of the collateral toxicity that plagued many other integrase inhibitors, rendering it an interesting lead compound. Previous approaches to the synthesis of $\mathbf{1}$ include the $\mathrm{HBr}$-promoted cyclization used by Raths and

22 (a) Elder, A.M.; Rich, D.H. Org. Lett. 1999, 1, 1443-1446. (b) Leduc, A.B.; Kerr, M.A. Eur. J. Org. Chem. 2007, 237-240. (c) Okabe, K.; Natsume, M.; Tetrahedron, 1991, 47, 7615-7624.

${ }^{23}$ Notably, the $J_{\mathrm{H} 2-\mathrm{H} 3}$ values were not a useful diagnostic tool for distinguishing the cis and trans isomers in these systems. Instead, the anisotropic effect of the $\mathrm{C}-2$ aryl group causes chemical shifts of $3-\mathrm{CH}$ and $\mathrm{CO}_{2} \mathrm{CH}_{3}$ which are diagnostic for cis versus trans isomers (Refs. 7, 9 and 18b). Thus, the trans compound displayed an upfield 3-Cㅡㅡ resonance, compared to the cis isomer.

${ }^{24}$ Johnson, G.; Sunderwirth, S. G.; Gibian, H.; Coulter, A.W.; Gassner, F.X. Phytochemistry 1963, 2, 145-150.

${ }_{25}$ (a) Kelley, C.J.; Mahajan, J.R.; Brooks, L.C.; Neubert, L.A.; Breneman, W.R.; Carmack, M. J. Org. Chem. 1975, 40, 1804-1815. (b) Wagner, H.; Wittman, D.; Schaffer, W. Tetrahedron Lett. 1975, 16, 547550 .

${ }^{26}$ (a) Lu, Y.; Foo, L.Y. Phytochemistry 2002, 59, 117-140. (b) Jiang, R.-W.; Lau, K.-M.; Hon, P.-M.; Mak, T.C.W.; Woo, K.-S.; Fung, K.-P. Curr. Med. Chem. 2005, 12, 237-246. (c) Kang, H.S.; Chung, H.Y.; Jung, J.H.; Kang, S.S.; Choi, J.S. Arch. Pharm. Res. 1997, 20, 496-500.

${ }_{27}$ A small selection include: (a) Lin, Y.-L.; Wang, C.-N.; Shiao, Y.-J.; Liu, T.-Y.; Wang, W.-Y. J. Chin. Chem.Soc. 2003, 50, 1079-1083. (b) Lin, Y.-L.; Chang, Y.-Y.; Kuo, Y.-H.; Shiao, M.-S. J. Nat. Prod. 2002, 65, 745-747. (c) Yamamoto, H.; Inoue, K.; Yazaki, K. Phytochemistry 2000, 53, 651-657. (d) Fukui, H.; Yazaki, K.; Tabata, M. Phytochemistry 1984, 23, 2398-2399.

${ }^{28}$ Abd-Elazem, I.S.; Chen, H.S.; Bates, R.B.; Huang, R.C.C. Antiviral Res. 2002, 55, 91-106. co-workers, resulting in the synthesis of racemic heptamethyl lithospermate, ${ }^{29}$ and the $\mathrm{C}-\mathrm{H}$ bond activation strategies used by Bergman, Ellman and co-workers, and also by $\mathrm{Yu}$ and co-workers for the first total syntheses of (+)-lithospermic acid. ${ }^{30}$

Sonogashira coupling of aryl iodide $\mathbf{9}$ and arylalkyne $\mathbf{2 5}$, $^{31}$ proceeded in $75 \%$ yield (Scheme 2). Sonogashira coupling, followed by protection of the aldehyde and removal of the acetate using $\mathrm{Cs}_{2} \mathrm{CO}_{3}$ in $\mathrm{MeOH}-\mathrm{THF}$, gave the ortho-hydroxydiarylalkyne 26. Subjecting $\mathbf{2 6}$ to carbonylative annulation generated the desired tetrasubstituted benzofuran $\mathbf{2 7}$ in good yield. The previously developed conditions proved well-suited for reducing 27 to give the desired 2,3-dihydrobenzo[b]furan 28 (81\%, ca. 3:1 trans:cis), following an acidic workup to remove the cyclic acetal protecting group. Knövenagel condensation of aldehyde $\mathbf{2 8}$ with malonic acid, and concomitant epimerisation at C-3, gave cinnamic acid 29 with improved $d r$ (ca. 6:1 2,3-trans:2,3-cis), which was subsequently coupled with known alcohol $30^{30 a}$ to afford $\left(2 S, 3 S, 2^{\prime} R\right)-31$ and the corresponding (2R,3R,2'R)diastereomer. The diastereomeric pair were separable by HPLC, providing diasteromerically pure 31. All spectroscopic data obtained matched that reported by Bergman, Ellman and co-workers. ${ }^{30 a}$

Scheme 2. Synthesis of (+)-Heptamethyl Lithospermate (31)

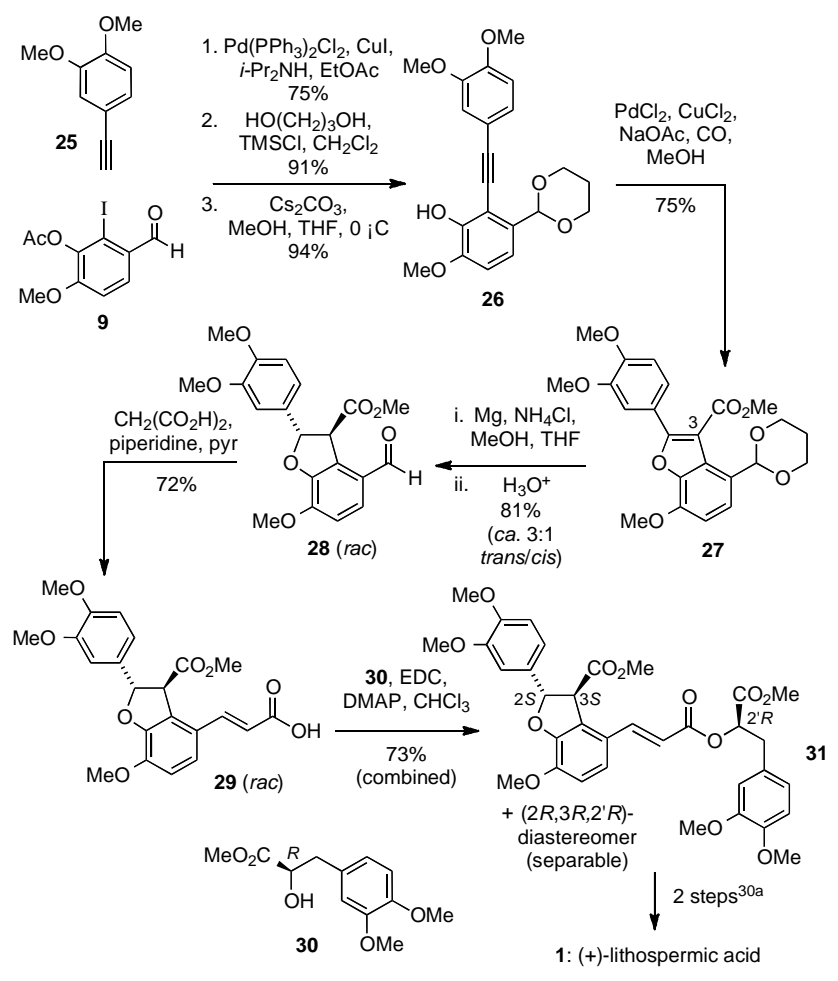

${ }^{29}$ Jacobsen, R.M.; Raths, R.A. J. Org. Chem. 1979, 44, 4013-4014.

${ }^{30}$ (a) O'Malley, S.J.; Tan, K.L.; Watzke, A.; Bergman, R.G.; Ellman, J.A. J. Am. Chem. Soc. 2005, 127, 13496-13497. (b) Wang, D.-H.; Yu, J.Q. J. Am. Chem. Soc. 2011, 133, 5767-5769.

${ }^{31}$ Pelter, A.; Ward, R. S.; Little, G. M.; J. Chem. Soc., Perkin Trans. 1 1990, 2775-90. 
The two-step conversion of $\mathbf{3 1}$ to $\mathbf{1}$, involving ester hydrolysis followed by global demethylation, has been reported, ${ }^{30 a}$ and hence the synthesis of (+)-heptamethyl lithospermate (31) by the sequence presented here constitutes a formal total synthesis of $(+)$-lithospermic acid (1).

We have demonstrated a versatile, modular synthetic approach to 2-aryl-2,3-dihydrobenzo[b]furans via Mgmediated reduction of benzo[b]furans, and demonstrated its use in natural product synthesis with a synthesis of $(+)$ heptamethyl lithospermate (31) in 7 steps and in 8.4\% overall yield from $\mathbf{9}$, constituting a formal total synthesis of the anti-HIV natural product (+)-lithospermic acid (1).

Acknowledgment. We thank the Australian Research Council for funding (DP556187), the CSIRO for funding and a scholarship to J.F. and Dr Natasha Hungerford (Griffith University) for her assistance in the preparation of this manuscript.

Supporting Information Available: Experimental procedures, product characterisation data, and ${ }^{1} \mathrm{H}$ and ${ }^{13} \mathrm{C}$ NMR spectra. This material is available free of charge via the Internet at http://pubs.acs.org. 